\title{
Green gold nanoparticle modified anthocyanin-based carbon paste electrode for voltammetric determination of heavy metals
}

\author{
H. Devnani $\cdot$ S. P. Satsangee
}

Received: 8 February 2013/Revised: 11 November 2013/Accepted: 3 January 2014/Published online: 16 January 2014

(C) Islamic Azad University (IAU) 2014

\begin{abstract}
Present communication reports a completely green and inexpensive method for synthesis of gold nanoparticles and their novel application in fabrication of gold nanoparticle modified anthocyanin-based carbon paste electrode for heavy metal estimation. Phytochemicals in black rice extract served as building blocks for gold nanoparticles. The conditions for gold nanoparticle preparation from black rice extract were optimized using ultraviolet-visible data. The characterization of the nanoparticles prepared was done using X-ray diffraction and atomic force microscopy techniques. The nanoparticles prepared were found to be in the range $31-52 \mathrm{~nm}$ and spherical in morphology. The fabricated metal sensor was used for the determination of lead, cadmium and copper using square-wave anodic stripping voltammetry. Various electrochemical parameters such as amount of modifier, supporting electrolyte, accumulation time and accumulation potential were optimized in terms of current response. Cyclic voltammetry and electrochemical impedance spectroscopy were used to characterize the fabricated sensor. Linear calibration curves were obtained in the concentration range of $50-500 \mu \mathrm{g} \mathrm{L}^{-1}$ for lead and $200-700 \mu \mathrm{g} \mathrm{L}^{-1}$ for cadmium and copper. The modified sensor showed enhanced sensitivity for electrochemical estimation of lead, cadmium and copper with low limits of detection 9.178, 86.327 and $85.373 \mu \mathrm{g} \mathrm{L}^{-1}$, respectively.
\end{abstract}

Keywords Gold · Nanoparticles · Green synthesis · Black rice $\cdot$ Carbon paste electrode $\cdot$ Voltammetry

H. Devnani - S. P. Satsangee $(\bowtie)$

University Science Instrumentation Centre (USIC), Dayalbagh

Educational Institute, Agra 282110, India

e-mail: usic.echem@gmail.com

\section{Introduction}

Heavy metal contamination in the environment is a major concern globally due to their toxicity and potential threat to human health (Xia et al. 2010). Severe lead poisoning can cause encephalopathy, with permanent damage, while moderate lead poisoning result in neurobehavioral and intelligence deficit (Chen et al. 2007). Cadmium is another toxic heavy metal with a greatest potential hazard to humans and the environment. It causes kidney damage, bone diseases and cancer, and chronic exposure to increased levels of cadmium can cause renal dysfunction, bone degeneration and liver damage (Iqbal et al. 2007). In contrast, copper is an essential trace elements. Its deficiency causes impairment of functions; however, it exhibits toxic properties in concentrations higher than the maximum permissible concentration (Jannata et al. 2009). Thus, the continuous monitoring of these metals at trace levels in environment is required.

Adsorptive stripping voltammetry (ASV) is not only an extremely sensitive electrochemical technique for measuring trace metals but also can carry out simultaneous detection of several metals in various matrices (Xia et al. 2010). The acceptance of stripping methods has, however, suffered from the use of mercury working electrodes, which lack market penetration compared with other techniques due to its mechanical instability and toxicity issues and thus giving way to solid electrodes.

The development and application of carbon paste electrodes (CPEs) has received considerable attention in recent years. These kinds of electrodes are inexpensive and possess many advantages such as low background current, wide range of used potential, easy fabrication and rapid renewal (Mojica et al. 2007a, b; Mohadesi et al. 2011). A common approach to increase selectivity of a CPE is to 
attach host molecules that selectively interact with specific guest molecules. Such electrodes offer the advantages of versatile bulk modification, fast response, renewability and a low background current. The ease of fabrication and the control of modifiers loading have been valuable for electrochemical studies and analytical applications (Mojica et al. 2005).

Nanostructured materials are of great interest in the advanced materials world due to chemical, physical and biological properties when compared to the corresponding atoms/molecules or their bulk states. In the field of electrochemistry, in particular electroanalysis, metal nanoparticles have been actively utilized as functional nanomaterials (Oyama 2010). Metal nanoparticles have shown superior or advantageous properties for a wide range of technological applications, and they provide three important functions for electroanalysis: improved mass transport, high effective surface area and catalytic properties (Majid et al. 2006; Dai et al. 2004, 2006; El-Deab et al. 2003; Welch et al. 2005).

Among various metal nanoparticles, gold $(\mathrm{Au})$ is the most widespread material used in optics, electrochemistry, catalysis and biochemical sensing because it is stable, less toxic and biocompatible (Daniel and Astruc 2004; Kneipp et al. 2006; Castaneda et al. 2007; Ishida and Haruta 2007). As the nanorevolution, in the realms of medical and technological application, unfolds, it is imperative to develop environmentally benign and biologically friendly green chemical processes. Naturally grown plants and various plant species that occlude phytochemicals may serve as long lasting and environmentally benign reservoirs for the production of a myriad of metallic nanoparticles (Nune et al. 2009).

Rice (Oryza sativa L.) is the principal cereal food in Asia and the staple food of nearly half of the world's population. Colored rice is a hulled grain having red or purple color in addition to light gray on its bran, especially black rice has long been consumed being considered a healthy food. It is reported that black rice (heugjinjubyeo) contains a lot of anthocyanin pigments. Anthocyanins are water-soluble plant pigments and representatives of flavonoids. They are responsible for the blue, purple and red color of many plant tissues. Depending on the $\mathrm{pH}$, anthocyanins are red to purple or blue (Park et al. 2008). Black rice contains rich anthocyanins in the aleurone layer. Two anthocyanins, cyanidin 3-glycoside and peonidin 3-glycoside, have been identified as the major polyphenolic compounds extracted from black rice (Zhang et al. 2006).
In this work, black rice extract was used as a reducing agent for preparing gold nanoparticles from aqueous solution of sodium tetrachloroaurate thus offering a green synthetic route. The gold nanoparticles prepared were then used as a modifier for anthocyanin-based carbon paste electrode, and increase in sensitivity was observed for electrochemical estimation of lead, cadmium and copper using square-wave anodic stripping voltammetry (SWASV).

This work was carried out from November 2011 to September 2012 at Remote Electroanalytical Laboratory, University Science Instrumentation Centre, Dayalbagh Educational Institute, Dayalbagh, Agra, India.

\section{Materials and methods}

\section{Instrumentation}

The conditions for gold nanoparticles preparation were optimized using ultraviolet-visible (UV-Vis) spectrophotometry (Schimadzu UV-Vis spectrophotometer). Average size of the gold nanoparticles synthesized was determined by X-ray diffraction (XRD) (Bruker AXS DQ Advance), and the morphological characteristics were studied using atomic force microscopy (AFM) (Nanosurf Easy Scan, Switzerland). Electrochemical experiments were performed using a $\mu$-Autolab Type III potentiostat interfaced with NOVA 1.8 software. A three-electrode system containing the fabricated sensor, $\mathrm{Ag} \mid \mathrm{AgCl}\left(3.0 \mathrm{~mol} \mathrm{~L}^{-1} \mathrm{KCl}\right)$, platinum wire as working, reference and auxiliary electrodes, respectively, was used. All $\mathrm{pH}$ measurements were made on a Mettler Toledo digital $\mathrm{pH}$ meter fitted with a glass electrode and a saturated calomel electrode as reference which was pre-standardized with buffers of known $\mathrm{pH}$. All measurements were carried out at room temperature.

\section{Reagents and chemicals}

Graphite powder $(<20 \mu \mathrm{m})$ and mineral oil (Nujol, light $d=0.838$ ) were obtained from Sigma-Aldrich. Nitrate salts of lead, cadmium and copper ( $>99 \%)$ obtained from Merck were used for preparation of stock solutions of $1,000 \mu \mathrm{g} \mathrm{mL}^{-}$. Test solutions of metals were prepared by dilution of the stock solutions. Sodium tetrachloroaurate 
(99\%) was obtained from Sigma-Aldrich. Potassium chloride $(>99 \%)$, sodium chloride $(>99 \%)$, sodium hydroxide $(>97 \%)$, sodium acetate $(>99 \%)$, potassium dihydrogen phosphate (>99\%), dipotassium hydrogen phosphate (>99\%), boric acid (99\%), potassium ferricyanide (>99\%), hydrochloric acid, acetic acid, nitric acid, sulfuric acid, perchloric acid and phosphoric acid were purchased from Merck. Ultrapure water (resistivity $=18 \mathrm{M} \Omega$ ) was obtained from ELGA Milli-Q water system.

\section{Procedures}

\section{Extraction of anthocyanins from black rice}

Black rice grains were obtained from the local market of China. It was grounded using mortar and pestle, and its anthocyanins were extracted according to the method as reported in the literature (Rodriguez-Saona and Wrolstad 2011). One gram of grounded black rice was mixed with $30 \mathrm{ml}$ of ethanol containing $0.1 \% \mathrm{HCl}$ and kept for sonication at $20,000 \mathrm{~Hz}$. After $1 \mathrm{~h}$ of sonication, crude extract was filtered with Whatman No. 1 filter paper. Ethanol extract (red) was then used for preparation of the metal sensor.

\section{Preparation of gold nanoparticles}

Gold nanoparticles were prepared by using aqueous anthocyanin extract of black rice as reducing agent. Aqueous extract was obtained by the same protocol as described for the ethanolic extract. Gum arabic was used as a stabilizer. For gold nanoparticle preparation, $0.012 \mathrm{~g}$ gum arabic was mixed with $6 \mathrm{ml}$ of aqueous anthocyanin extract and stirred for $5 \mathrm{~min}$. After $5 \mathrm{~min}$ of stirring, $100 \mu \mathrm{L}$ of $0.1 \mathrm{M} \mathrm{NaAuCl}{ }_{4} \cdot 2 \mathrm{H}_{2} \mathrm{O}$ was added drop wise (Nune et al. 2009).

Four sets were set up to optimize the stirring time for gold nanoparticle preparation and to study the effect and role of gum arabic. The stirring time was varied in the four sets being $15 \mathrm{~min}$ for set A, $30 \mathrm{~min}$ for set B as well as set $\mathrm{C}$ and $60 \mathrm{~min}$ for set $\mathrm{D}$. The gum arabic $(0.012 \mathrm{~g})$ was added in sets A, C and D while it was not added in set B.

\section{Fabrication of gold nanoparticle modified carbon paste electrode}

Anthocyanin-modified carbon paste electrodes (AMCPEs) were prepared by mixing $83 \mu \mathrm{L}$ mineral oil, $200 \mathrm{mg}$ graphite powder and black rice extract varying in amount from 5 to $40 \mu \mathrm{L}$ in agate mortar and pestle. Paste was filled in a glass tube with internal diameter $3 \mathrm{~mm}$ and depth $4 \mathrm{~cm}$. Copper wire was inserted from back side for electrical contact, and electrode surface was smoothened on a photo paper. All the prepared electrodes were stored in a desiccator for $24 \mathrm{~h}$ and then used for analysis. For later storage, they were kept in a refrigerator.

Gold nanoparticle modified anthocyanin-based carbon paste electrodes (GNMACPEs) were prepared by mixing optimized amount of anthocyanin extract, gold nanoparticles (synthesized from black rice extract as described) varying in amount from 1 to $10 \mathrm{mg}, 83 \mu \mathrm{L}$ mineral oil and graphite powder according to the modifier amount used, to make up a total of $200 \mathrm{mg}$. The protocol followed for the fabrication of GNMACPE was same as described for AMCPE.

\section{Working voltammetric procedure}

The fresh surface electrode is first electrochemically activated by six replicated direct current sweeping from 1,000 to $1,000 \mathrm{mV}$ with scan rate $50 \mathrm{mV} \mathrm{s}^{-}$, immersing in $0.2 \mathrm{M} \mathrm{HCl}$ solution. The sensor was then immersed in standard metal solution in a pre-concentration cell with constant stirring at open circuit. The sensor was then taken out, rinsed with water and transferred to voltammetric cell containing $0.2 \mathrm{M} \mathrm{HCl}$ as supporting electrolyte. Square wave was ramped from $-1,000$ to $0 \mathrm{mV}$ with scan rate $50 \mathrm{mV} \mathrm{s}-$, pulse amplitude $25 \mathrm{mV}$, pulse duration $20 \mathrm{~ms}$, measurement time $10 \mathrm{~ms}$, frequency $25 \mathrm{~Hz}$ for square wave. The experiment was triplicated without electrode regeneration. For new sample, the surface was regenerated by pushing the electrode material from back side and squeezing out small amount of the modifier. The experiment was repeated with electrode regeneration as described before.

\section{Results and discussion}

Green synthesis of gold nanoparticles

The initial yellow color of solution (after addition of $\mathrm{NaAuCl}_{4}$ to anthocyanin extract and gum arabic) changes to brownish red in $60 \mathrm{~min}$ after stirring is stopped. This color change indicated the gold nanoparticle formation (Fig. 1). 

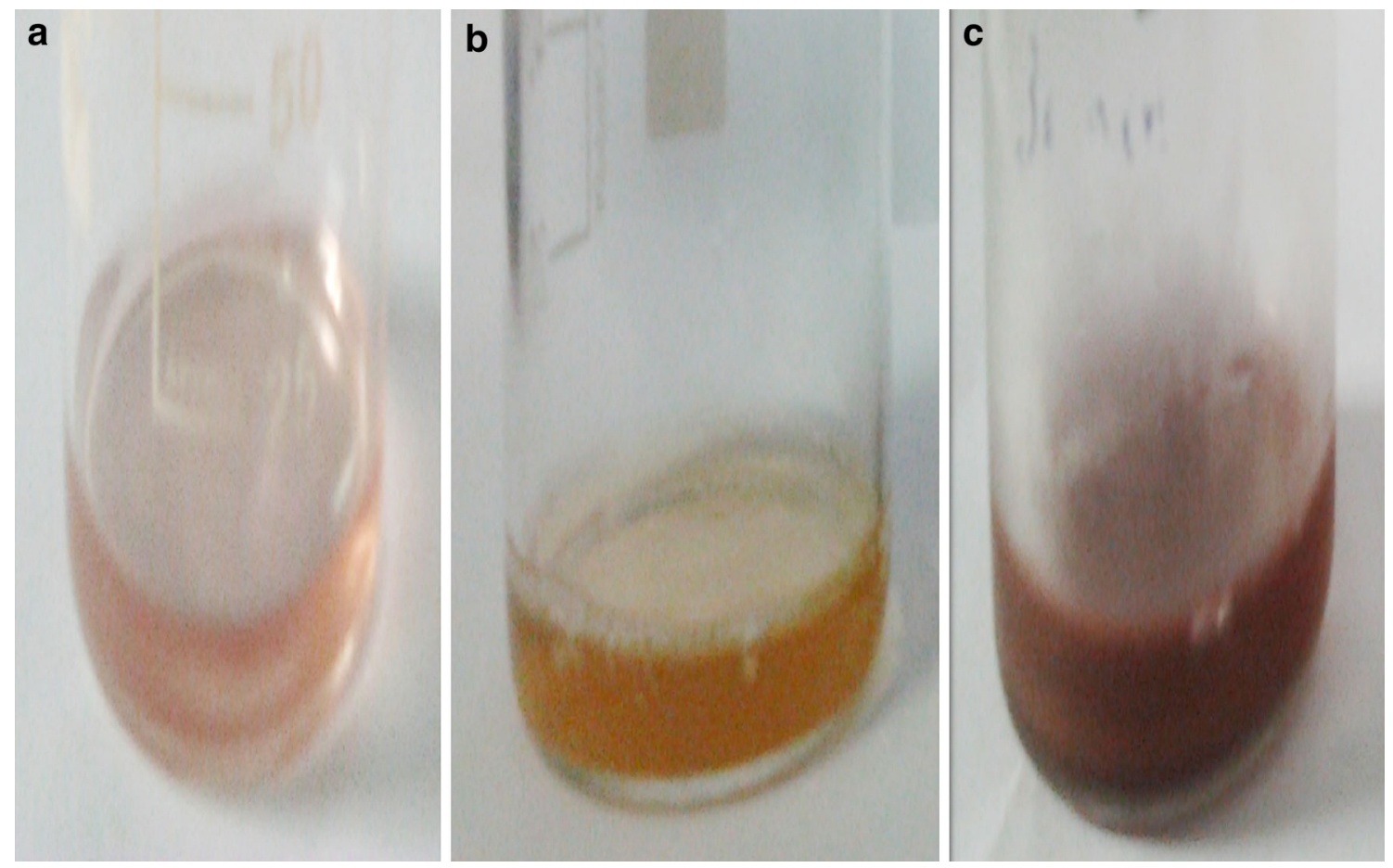

Fig. 1 a Aqueous anthocyanin extract of black rice. b Yellow color appearance on addition of gold salt to extract. c Color change from yellow to reddish brown on gold nanoparticles formation

Fig. 2 UV-VIS plots for the four sets over several days, where curve $a$ is for day $1, b$ for day 3 and $c$ for day 5
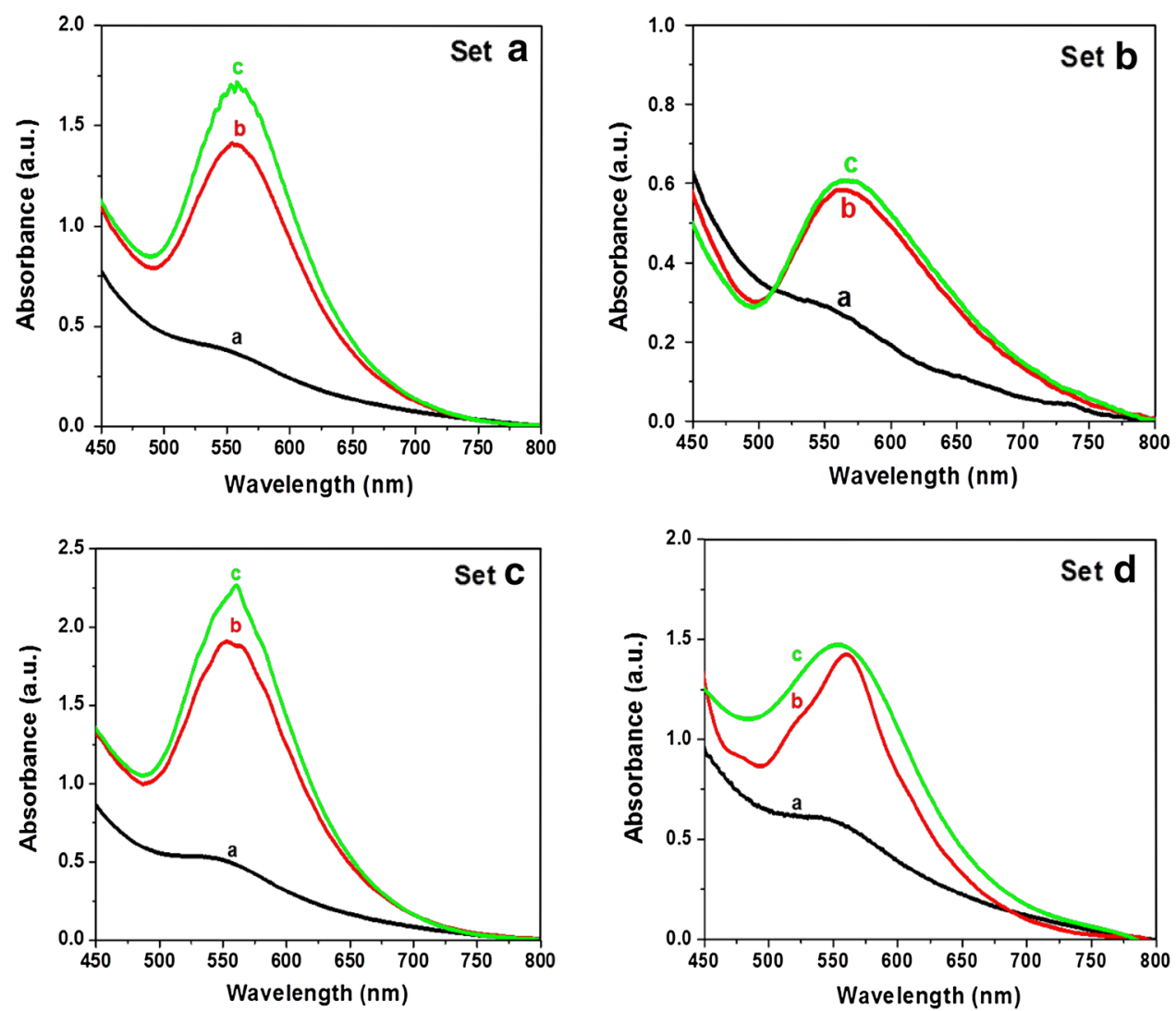
Optimization of conditions

The UV-Vis plots of different sets over some days have been depicted in Fig. 2. A clear absorption peak $\approx 560-570 \mathrm{~nm}$ can be seen in UV-Vis spectra which is characteristic absorption band of gold nanoparticles. The gold nanoparticles were also formed in absence of gum arabic in set B. This shows that the phytochemicals present in black rice extract act as reducing agent and gum arabic plays role in stabilization of gold nanoparticles formed. Set $\mathrm{D}$ in comparison with Set $\mathrm{C}$ had a longer stirring time but the concentration of nanoparticles in Set $\mathrm{C}$ is found to be more implying longer stirring time does not favor nanoparticle formation. Set $\mathrm{C}$ was thus optimized for further studies as it showed maximum concentration of gold nanoparticles as is clear from Fig. 2.

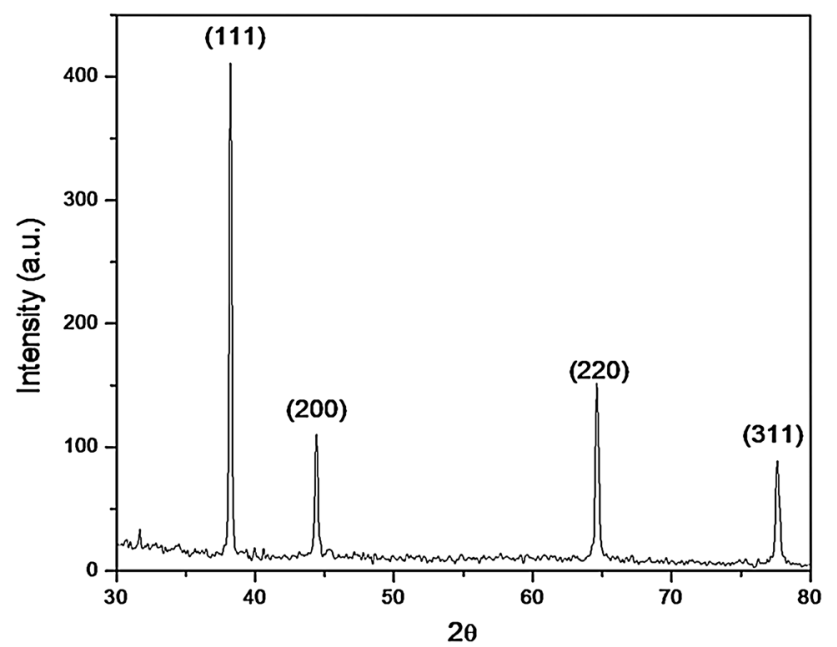

Characterization of gold nanoparticles

$X R D$

Conditions optimized on basis of UV-Vis results were used to prepare nanoparticle so as to study their XRD pattern. Particle size value was calculated using the Scherrer's equation:

$D \approx \frac{0.9 \lambda}{\beta \cos \theta}$

where $\beta$ is full width at half wave length, $D$ is grain size and $\lambda$ is the wavelength of $\mathrm{X}$-ray used.

The XRD pattern has been shown in Fig. 3. The four characteristic peaks at $2 \theta=38.1^{\circ}, 44.3^{\circ}, 64.5^{\circ}$ and $77.4^{\circ}$ correspond to the (111), (200), (220) and (311) planes of face-centered cubic (fcc) $\mathrm{Au}$ (Wu and Chen 2010). The particle size calculated from XRD was found to be in the range $31.71-52.1 \mathrm{~nm}$.

\section{$A F M$}

The morphological characteristics of the gold nanoparticles were studied using AFM. The 3D and 1D AFM images are shown in Fig. 4. The aggregates of spherical gold nanoparticles can be seen in the images. The average surface area (root-mean square value) was found to be $58.791 \mathrm{~nm}$; roughness, $47.909 \mathrm{~nm}$; peak valley height, $221.63 \mathrm{~nm}$; peak height (highest value), $142.27 \mathrm{~nm}$; valley depth (lowest value), $-79.36 \mathrm{~nm}$ and mean value, $240.12 \mathrm{pm}$. The large surface area offered by these gold nanoparticles is the key to its electrochemical performance when used as a component of carbon paste electrode.

Fig. 3 XRD pattern of Au nanoparticles

Fig. 4 AFM 1D and 3D images of gold nanoparticles
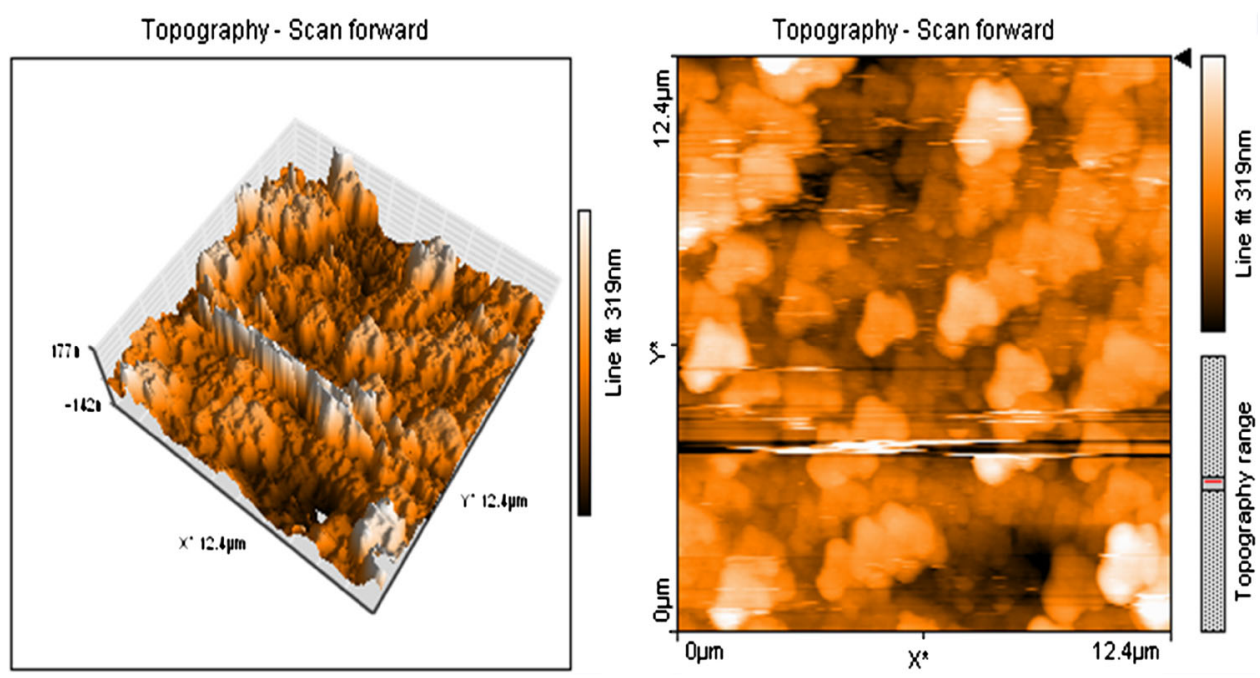


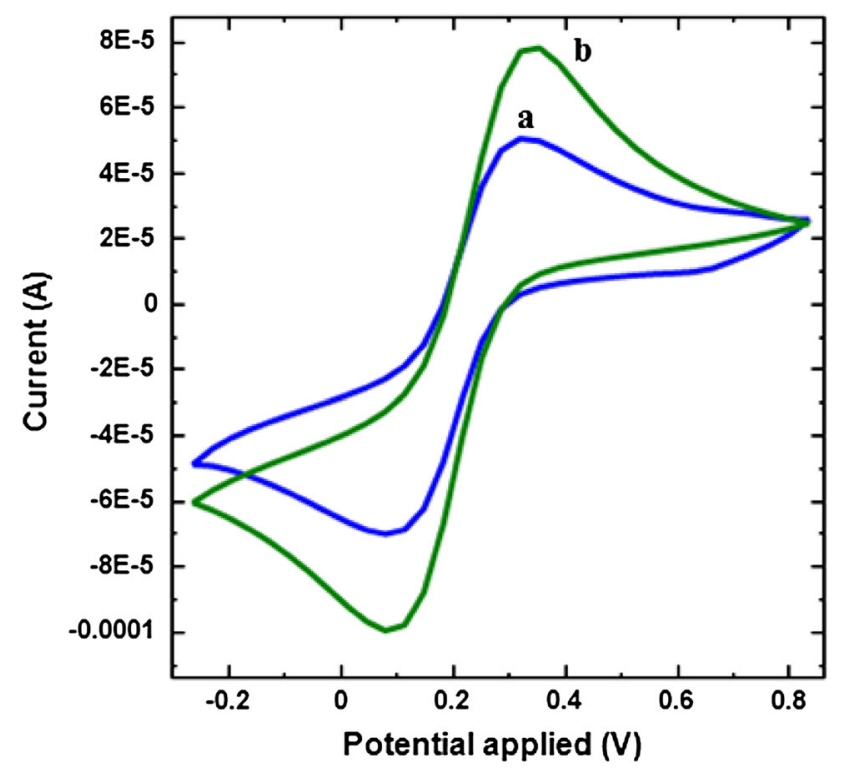

Fig. 5 Cyclic voltammograms of bare CPE (a) and GNMACPE (b) in $5 \mathrm{mM}$ ferricyanide prepared with $0.1 \mathrm{M} \mathrm{KCl}$ at the scan rate of $50 \mathrm{mV} \mathrm{s}^{-1}$

Electrochemical characterization of electrodes

Cyclic voltammetry (CV) and electrochemical impedance spectroscopy (EIS) techniques were used to characterize the fabricated electrode. Well-defined cyclic voltammogram was observed in $5 \mathrm{mM}$ potassium ferricyanide solution at unmodified carbon paste electrode (Fig. 5a). In case of GNMACPE, enhancement in peak current and peak area was observed (Fig. 5b), which signifies the lowering of charge transfer resistance allowing enhanced electron transfer.

These results were also supported by EIS study. The Nyquist plots were obtained by recording electrochemical impedance spectra in $5 \mathrm{mM}$ potassium ferricyanide solution at unmodified CPE (Fig. 6a) and GNMACPE (Fig. 6b). The circuit fit was found to be $\left[R_{\mathrm{ohm}}\left(Q\left[\left(R_{\mathrm{ct}} W\right]\right)\right]\right.$ shown in Fig. $5 \mathrm{c}$. Here, $R_{\mathrm{ohm}}$ is the solution resistance and $R_{\mathrm{ct}}$ is charge transfer resistance. $R_{\mathrm{ohm}}$ is $67.9 \Omega$ in case of unmodified CPE and $63.5 \Omega$ in case of GNMACPE. $R_{\mathrm{ct}}$ is $7.2 \mathrm{~K} \Omega$ for GNMACPE which is much lower in comparison with $20.3 \mathrm{~K} \Omega$ for unmodified CPE. Both the resistance solution and charge transfer were thus found to reduce in case of the modified electrode which explains the enhancement in current response.

\section{Effective surface area}

The electroactive surface area of the electrodes was calculated according to the Randles-Sevcik equation at $25{ }^{\circ} \mathrm{C}$ (Rezaei and Damiri 2008).

$\mathrm{Ip}=\left(2.69 \times 10^{5}\right) A D^{1 / 2} n^{3 / 2} v^{1 / 2} C$

where $\mathrm{n}$ is the number of electrons participating in the redox reaction, $A$ is the area of the electrode $\left(\mathrm{cm}^{2}\right), D$ is the diffusion coefficient of the molecule in solution $\left(\mathrm{cm}^{2} \mathrm{~s}^{-1}\right)$, $\mathrm{C}$ is the concentration of the probe molecule in the bulk solution $\left(\mathrm{mol} \mathrm{cm}{ }^{-3}\right)$ and $v$ is the scan rate of the potential perturbation $\left(\mathrm{V} \mathrm{s}^{-1}\right) . \mathrm{CV}$ with increasing scan rate was
Fig. 6 Nyquist plots obtained for bare CPE (a) and GNMACPE (b) in $5 \mathrm{mM}$ ferricyanide and equivalent circuit $[\mathrm{R}(\mathrm{C}[\mathrm{RW}])](\mathbf{c})$
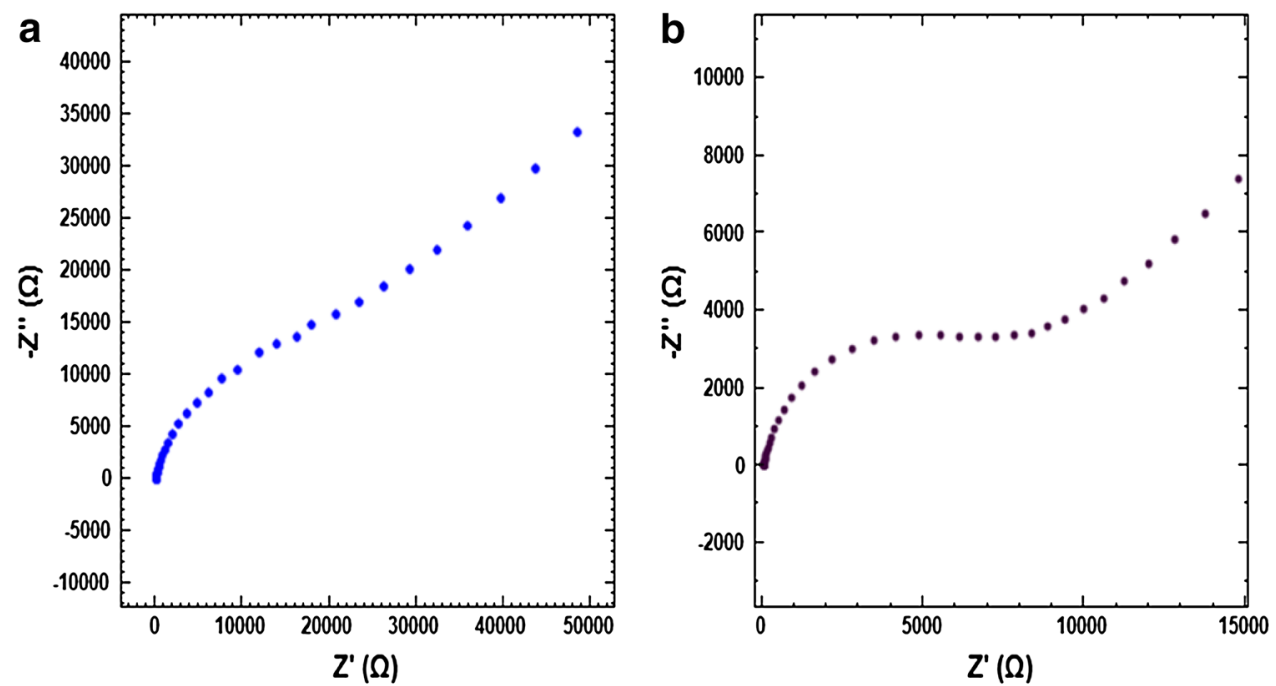

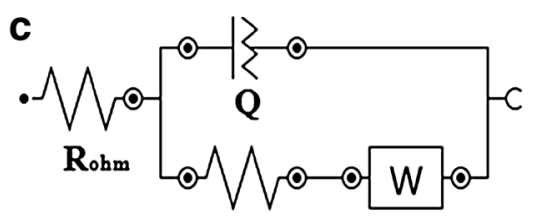

$\mathbf{R}_{\mathbf{c t}}$ 
performed in the ferricyanide solution. Electroactive surface area was calculated to be $0.365 \mathrm{~cm}^{2}$ for GNMACPE, which is higher as compared to $0.328 \mathrm{~cm}^{2}$ for AMCPE and $0.154 \mathrm{~cm}^{2}$ for bare CPE.

Optimization of electrochemical parameters

\section{Amount of modifier}

The ratio of modifier to graphite powder is an important electrochemical parameter. For AMCPE, an increase in peak current was observed up to $10 \mu \mathrm{L}$ of anthocyanin extract for lead and cadmium, and after this current value decreased. Similarly for copper, $15 \mu \mathrm{L}$ of anthocyanin extract as modifier was found to be optimum.

In case of GNMACPE, $5 \mathrm{mg}$ was found to be optimum amount for fabrication of electrode to show enhanced sensitivity for the three metals under study.

Increased proportion of modifier incorporated more binding sites available for metal attachment on the sensor surface. On the other hand, a decline in current response at large percentage of the binding component owes to deterrence of electrical conductivity. The decrease may be attributed to the decreasing amount of the carbon powder. Carbon is one of the components of the sensor and is responsible for its conductivity. Decreasing the amount of the carbon powder will decrease the conductivity of the sensor (Elvina and Mojica 2005).

\section{Supporting electrolytes}

For the selection of appropriate supporting electrolyte, the determination of metal ions was carried out with different electrolytes (acids, bases and salts) such as $\mathrm{HCl}, \mathrm{HNO}_{3}$, $\mathrm{H}_{2} \mathrm{SO}_{4}, \mathrm{HClO}_{4}, \mathrm{H}_{3} \mathrm{PO}_{4}, \mathrm{NaOH}, \mathrm{KOH}, \mathrm{NaCl}$ and $\mathrm{KCl}$. Best response was obtained utilizing hydrochloric acid for lead, cadmium as well as copper. Sharper and well-defined peaks were observed using $\mathrm{HCl}$ as compared to bases, salts and other acids. Among acids $\mathrm{Cl}^{-}$is the best migrating ligand being smaller in size as compared to other ligands. The comparison with $\mathrm{NaOH}$ can be explained in the basis of characteristic of acidic chloride ions being better ligand for metal as compared to $\mathrm{OH}^{-}$ions. $\mathrm{HCl}$ has the ability to enhance the current due to the complexation reaction between $\mathrm{Pb}(\mathrm{II})$ and chloride giving an extra driving force for the oxidation. This was confirmed by a study (Bartlett et al. 2000) involving the use of chloride media such as $\mathrm{NH}_{4} \mathrm{Cl}$ and $\mathrm{HCl}$ in determining trace amount of heavy metals, the presence of species capable of complexing the metal ion formed during the anodic scan favors the oxidation reaction. This is in contrast to $\mathrm{NaOH}$ and $\mathrm{NaCl}$, where the positive inert species, $\mathrm{Na}^{+}$, might compete in carrying the current that could result to interferences (Mojica et al. 2007a, b). $\mathrm{KOH}$ and $\mathrm{KCl}$ show behavior similar to $\mathrm{NaOH}$ and $\mathrm{NaCl}$ for the same reason. $\mathrm{HCl}$ has been found to be the best electrolyte for the voltammetric determination of lead using CPE modified with orange peel essential oil (Elvina and Mojica 2005), pineapple peelings (Mojica et al. 2006) and banana tissue (Mojica et al. 2007a, b). $\mathrm{Cd}(\mathrm{II})$ and $\mathrm{Cu}(\mathrm{II})$ also show patterns similar to lead in binding.

The effect of the $\mathrm{HCl}$ concentration on the peak height was also investigated in the range $0.05-0.5 \mathrm{~mol} \mathrm{~L}^{-}$as ionic strength is related to $\mathrm{pH}$ of the solution. Usually, low concentrations are used to avoid complexation with analyte. On increase in $\mathrm{HCl}$ concentration, increase in the current value was observed up to $0.2 \mathrm{~mol} \mathrm{~L}^{-}$for the metals under study. On further increase of $\mathrm{HCl}$ concentration, current value decreased. Thus, $0.2 \mathrm{~mol} \mathrm{~L}^{-} \mathrm{HCl}(\mathrm{pH} \sim 1)$ was selected as the supporting electrolyte. The $\mathrm{pH}$ of $0.2 \mathrm{M}$ $\mathrm{HCl}$ solution is $<2$, which is characteristic for stripping of metal ions like $\mathrm{Pb}$ (II), $\mathrm{Cd}$ (II) and $\mathrm{Cu}$ (II).

\section{Accumulating solution (effect of $\mathrm{pH}$ )}

The functional groups ionize when the electrode is dipped in the aqueous metal solution and this allows binding of metals. The ionization is $\mathrm{pH}$ dependent, and thus, the $\mathrm{pH}$ of accumulating electrolyte is an important parameter. To study the effect of $\mathrm{pH}$, acetate, phosphate and BrittonRobinson (BR) buffers were used. The peak current increased from $\mathrm{pH} 2-5$ and after $\mathrm{pH} 5$, it decreased. The optimum $\mathrm{pH}$ for accumulation is thus $\mathrm{pH}$. This can be explained on basis of ionic exchange. Metal ions compete for the negatively charged functional groups in the modifier. The decrease in peak current at higher $\mathrm{pH}$ may be attributed to formation of complexes with metal ions. The decrease at lower $\mathrm{pH}(<2)$ can be explained by the protonation of weakly basic coordination groups at the modified electrode surface (Ramos et al. 1993). These results are in the range of $\mathrm{pH}$ that Gardea-Torresdey et al. (1988) specified in his study. Their group classified lead among the metals that are tightly and rapidly bound at $\mathrm{pH}>5$ and stripped at $\mathrm{pH}<2$. Ions like $\mathrm{Cu}(\mathrm{II}), \mathrm{Cd}(\mathrm{II}), \mathrm{Cr}(\mathrm{III}), \mathrm{Co}(\mathrm{II})$, $\mathrm{Al}(\mathrm{III}), \mathrm{Zn}(\mathrm{II}), \mathrm{Fe}(\mathrm{III})$ and $\mathrm{UO}_{2}(\mathrm{VI})$ also belonged to this class. The $\mathrm{pH}$ of environmental samples that are aqueous in 
nature is close to 7 . Depending on the nature of ions present, it may be acidic or basic but accumulation of metal ions under consideration is convenient close to $\mathrm{pH} 5$ or greater as mentioned.

\section{Accumulation time}

The effect of the accumulation time on the metals stripping current values in the range $0-15 \mathrm{~min}$ was investigated. SWASV peak currents increased initially almost linearly with increasing accumulation time between 0 and 3 min for lead as well as cadmium and 0-4 min for copper. After this, the current values were almost constant. This behavior indicates that after $3 \mathrm{~min}$ accumulation time for lead, cadmium and $4 \mathrm{~min}$ for copper, steady-state equilibrium between adsorption/ complex formation and desorption/complex dissociation is reached.

\section{Deposition potential}

The effect of the deposition potential on the current value was studied in the range -1.5 to $-0.4 \mathrm{~V}$, depending upon the metal of interest. In case of lead, an increase in the current value was observed from -0.7 to $-0.9 \mathrm{~V}$ then it became constant from -1 to $-1.2 \mathrm{~V}$ and on further increase in deposition potential, current value decreased. For cadmium, there is an increase in the current response from -0.8 to $-0.9 \mathrm{~V}$ and for copper from -0.4 to $-0.6 \mathrm{~V}$. Decrease in the deposition efficiency after more negative potential may be due to hydrogen evolution at the electrode surface. Peak position shift in the negative direction was observed for lead in contrast to cadmium. Optimized deposition potential for lead and cadmium is $-0.9 \mathrm{~V}$ and for copper $-0.6 \mathrm{~V}$.

\section{Instrumental parameters}

Scan rate, pulse amplitude and frequency were optimized for square-wave voltammetric scan. The study was performed under optimized conditions after accumulation of $0.5 \mu \mathrm{g} \mathrm{mL}{ }^{-}$lead, $1 \mu \mathrm{g} \mathrm{mL}^{-}$cadmium and $0.5 \mu \mathrm{g} \mathrm{\textrm {mL } ^ { - }}$ copper (concentrations were chosen based on peak prominence and stability and low concentrations were preferred to avoid electrode fouling) on GNMACPE separately. For all three metals, scan rate was optimized to be $50 \mathrm{mV} \mathrm{s}-$, pulse amplitude as $25 \mathrm{mV}$ and $25 \mathrm{~Hz}$ frequency at GNMACPE.
Comparison of voltammetric behavior of lead, cadmium and copper at GNMACPE, AMCPE and bare CPE

Figure 7 presents square-wave anodic stripping voltammograms obtained for lead, cadmium and copper at bare CPE, AMCPE and GNMACPE in $0.2 \mathrm{~mol} \mathrm{~L}^{-1} \mathrm{HCl}$ solution. No peaks were observed in the potential range -1.1 to $+0.4 \mathrm{~V}$ versus $\mathrm{Ag} \mid \mathrm{AgCl}$ at the AMCPE and GNMACPE in the absence of $\mathrm{Pb}^{2+}, \mathrm{Cd}^{2+}$ and $\mathrm{Cu}^{2+}$. When the accumulation process was carried out for $120 \mathrm{~s}$ at $-0.9 \mathrm{~V}$ for $0.5 \mu \mathrm{g} \mathrm{mL}^{-}$lead as well as $1 \mu \mathrm{g} \mathrm{mL}^{-}$cadmium and at $0.6 \mathrm{~V}$ for $0.5 \mu \mathrm{g} \mathrm{mL}^{-}$copper at the bare CPE, peaks appeared in the stripping voltammogram at $-0.46,-0.722$ and $-0.163 \mathrm{~V}$, respectively. For AMCPE, oxidation peaks were at almost identical potentials of $-0.455,-0.710$ and $-0.139 \mathrm{~V}$. At GNMACPE, peaks at potential $-0.5,-0.74$ and $-0.08 \mathrm{~V}$ versus $\mathrm{Ag} \mid \mathrm{AgCl}$ for lead, cadmium and copper, respectively, were obtained with higher anodic stripping currents in comparison with those observed at the bare CPE. Figure 7 shows enhancement in peak current with GNMACPE and AMCPE as compared to bare carbon paste electrode. The enhancement though is more in case of GNMACPE in comparison with AMCPE and thus the focus was on former.

This enhancement could be explained by the fact that the black rice extract contains an abundant amount of oxygen-containing functional groups such as phenolic structures (anthocyanins) that could possibly form metal macromolecular complexes with high stability through ionic, hydrogen and coordinate covalent bonding. This mechanism is in accordance with that proposed by Mojica et al. (2007a, b) for determination of lead ions. Further due to small size of gold nanoparticles, it offers enhanced electroactive surface area which accounts for the enhancement in peak current. Gold nanoparticles facilitate the electron transfer process and thus the fraction of metal ions getting reduced increases.

Interference study (effect of other metal ions)

Large quantities of ions may be present in the background substance (matrix) of the original sample. Some of them are electrochemically active. The presence of other metal ions in the sample solutions can easily lead to a problem which makes the stripping voltammetric determination of target metal ion difficult. They interfere directly by occupying the binding sites and create changes in viscosity 

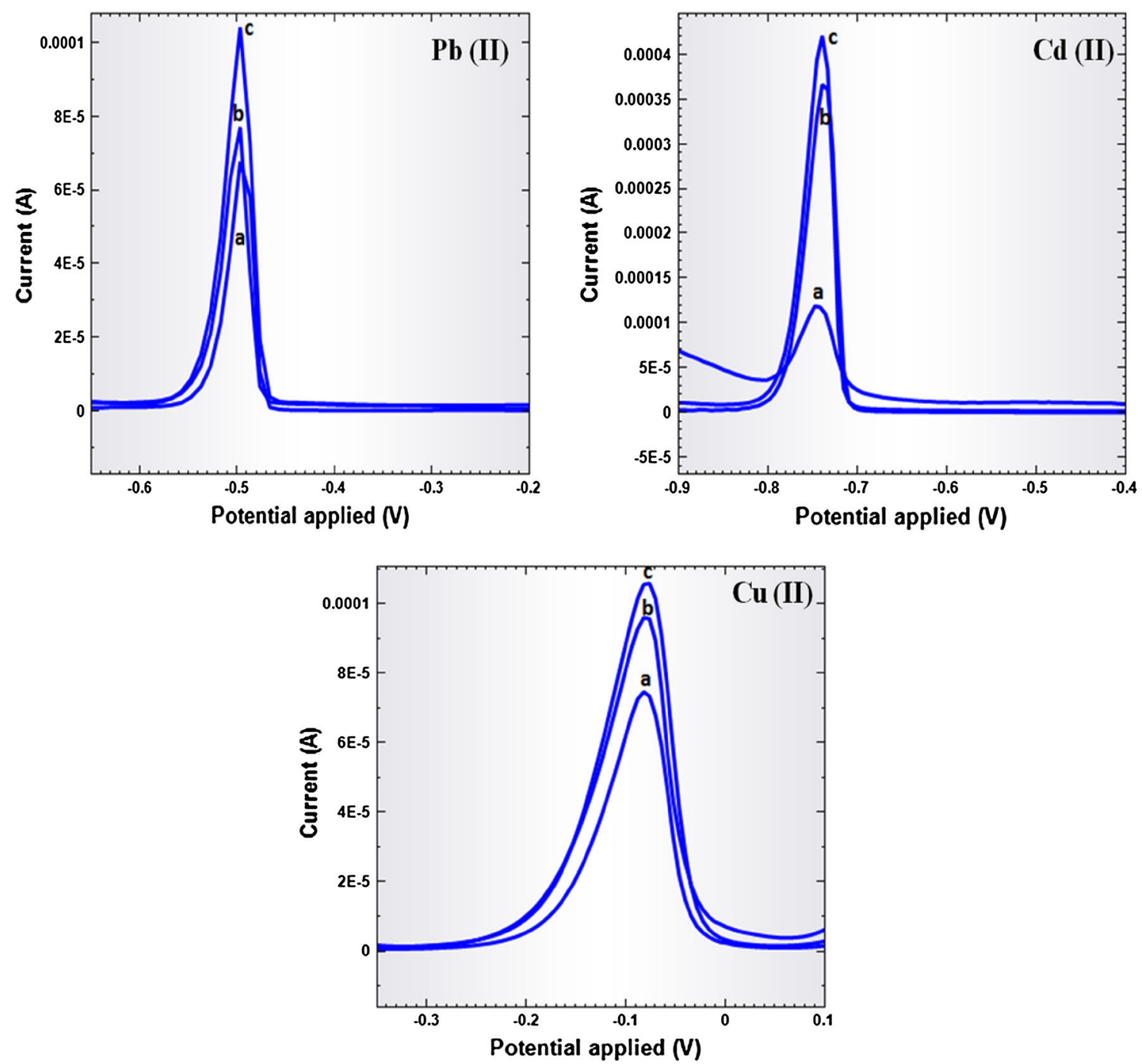

Fig. 7 Square-wave anodic stripping voltammograms for $0.5 \mu \mathrm{g} \mathrm{mL}{ }^{-}$of $\mathrm{Pb}(\mathrm{II}), 1 \mu \mathrm{g} \mathrm{mL}{ }^{-}$of $\mathrm{Cd}(\mathrm{II})$ and $0.5 \mu \mathrm{g} \mathrm{mL}{ }^{-}$of $\mathrm{Cu}(\mathrm{II})$ at bare CPE (curve a), AMCPE (curve b) and GNMACPE (curve c) using $0.2 \mathrm{M} \mathrm{HCl}$ as supporting electrolyte. Stripping parameters are

which has an effect on diffusion coefficient (Javanbakht et al. 2009). This may result in poor peak resolution or it may reduce the efficiency of the modified electrode to the target analyte. In order to study the degree of this mutual interference on the peak current of target metal, SWASV measurements were performed in the presence of the other metal ions. The tolerance was defined as the maximum concentration of potential interfering ions that caused a change in signal of $\pm 5 \%$ (Yardim and Senturk 2011).

For AMCPE, in comparison among metals, copper is the most interfering species for the determination of other
$-0.9 \mathrm{~V}$ accumulation potential for $\mathrm{Pb}(\mathrm{II})$ and $\mathrm{Cd}(\mathrm{II}) ;-0.6 \mathrm{~V}$ for $\mathrm{Cu}$ (II); 3 min accumulation time, $50 \mathrm{mVs}^{-1}$ scan rate, $25 \mathrm{mV}$ pulse amplitude and $25 \mathrm{~Hz}$ frequency

metal ions followed by lead, cadmium and zinc. No interference was observed in determination of $0.5 \mu \mathrm{g} \mathrm{mL}$ lead up to 200-fold of cadmium, fivefold of copper and 250 -fold of zinc. For $1 \mu \mathrm{g} \mathrm{mL}{ }^{-}$cadmium, tenfold of lead, twofold of copper and 50-fold of zinc did not cause interference in its determination. For $0.5 \mu \mathrm{g} \mathrm{mL}-$ copper, no interference was observed up to fivefold of lead, twofold of cadmium and twofold of zinc. Peak shape remained unaffected in presence of the interfering ions except copper. Increase in the amount of copper up to fivefold causes peak splitting for lead. 
Table 1 Effect of other metal ions on voltammetric determination of $0.5 \mu \mathrm{g} \mathrm{mL}{ }^{-} \mathrm{Pb}$ (II), $1 \mu \mathrm{g} \mathrm{mL}{ }^{-} \mathrm{Cd}$ (II) and $0.5 \mu \mathrm{g} \mathrm{mL}^{-} \mathrm{Cu}$ (II) at AMCPE and GNMACPE

\begin{tabular}{|c|c|c|c|}
\hline \multirow[t]{2}{*}{ Metal ion } & \multirow[t]{2}{*}{ Concentration $\left(\mu \mathrm{g} \mathrm{mL}^{-}\right)$} & \multicolumn{2}{|c|}{ Current $(\mu \mathrm{A})$} \\
\hline & & AMCPE & GNAMCPE \\
\hline \multicolumn{4}{|c|}{ Lead in absence of interfering metal ions } \\
\hline $\mathrm{Pb}(\mathrm{II})$ & 0.5 & 77.4 & 103.3 \\
\hline \multicolumn{4}{|c|}{ Lead in presence of interfering metal ions } \\
\hline \multirow[t]{4}{*}{$\mathrm{Cd}(\mathrm{II})$} & 100 & 74.1 & 102.8 \\
\hline & 105 & 72.3 & 102.1 \\
\hline & 175 & - & 98.5 \\
\hline & 180 & - & 97.3 \\
\hline \multirow[t]{4}{*}{$\mathrm{Cu}(\mathrm{II})$} & 2.5 & 73.9 & 102.3 \\
\hline & 5 & 69.7 & 101.2 \\
\hline & 25 & - & 98.4 \\
\hline & 30 & - & 96.2 \\
\hline \multirow[t]{4}{*}{$\mathrm{Zn}(\mathrm{II})$} & 125 & 75.2 & 102.5 \\
\hline & 130 & 71.7 & 101.8 \\
\hline & 150 & - & 98.9 \\
\hline & 155 & - & 97.8 \\
\hline \multicolumn{4}{|c|}{ Cadmium in absence of interfering metal ions } \\
\hline $\mathrm{Cd}(\mathrm{II})$ & 1.0 & 360.6 & 420.9 \\
\hline \multicolumn{4}{|c|}{ Cadmium in presence of interfering metal ions } \\
\hline \multirow[t]{4}{*}{$\mathrm{Pb}(\mathrm{II})$} & 10 & 343.4 & 418.5 \\
\hline & 20 & 341.7 & 414.4 \\
\hline & 50 & - & 401.4 \\
\hline & 60 & - & 398.8 \\
\hline \multirow[t]{4}{*}{$\mathrm{Cu}(\mathrm{II})$} & 2 & 344.2 & 417.1 \\
\hline & 5 & 340.6 & 411.5 \\
\hline & 10 & - & 400.2 \\
\hline & 15 & - & 398.6 \\
\hline \multirow[t]{4}{*}{$\mathrm{Zn}(\mathrm{II})$} & 50 & 342.9 & 416.3 \\
\hline & 60 & 339.8 & 413.8 \\
\hline & 100 & - & 402.7 \\
\hline & 110 & - & 399.1 \\
\hline \multicolumn{4}{|c|}{ Copper in absence of interfering metal ions } \\
\hline $\mathrm{Cu}(\mathrm{II})$ & 0.5 & 93.7 & 160.2 \\
\hline \multicolumn{4}{|c|}{ Copper in presence of interfering metal ions } \\
\hline \multirow[t]{4}{*}{$\mathrm{Pb}(\mathrm{II})$} & 2.5 & 91.5 & 158.8 \\
\hline & 5 & 88.6 & 156.3 \\
\hline & 7.5 & - & 154.2 \\
\hline & 10 & - & 151.3 \\
\hline \multirow[t]{4}{*}{$\mathrm{Cd}(\mathrm{II})$} & 1 & 90.6 & 159.4 \\
\hline & 2.5 & 87.7 & 157.1 \\
\hline & 12.5 & - & 153 \\
\hline & 15 & - & 151.1 \\
\hline \multirow[t]{4}{*}{$\mathrm{Zn}(\mathrm{II})$} & 1 & 92.3 & 159.2 \\
\hline & 2.5 & 89.8 & 158 \\
\hline & 5 & - & 153.7 \\
\hline & 7.5 & - & 150.5 \\
\hline
\end{tabular}

With GNMACPE, interference from other metal ions was found to be reduced. No interference was observed in determination of $0.5 \mu \mathrm{g} \mathrm{mL}-$ lead up to 350 -fold of cadmium, 50-fold of copper and 300-fold of zinc. For $1 \mu \mathrm{g} \mathrm{mL}^{-}$cadmium, 50-fold of lead, tenfold of copper and 100 -fold of zinc did not cause interference in its determination. For $0.5 \mu \mathrm{g} \mathrm{mL}^{-}$copper, no interference was observed up to 15-fold of lead, 25-fold of cadmium and tenfold of zinc. Peak shape remained unaffected in the presence of interfering ions.

The effect of interfering metals on the determination of metals under study can be explained on the basis of HardSoft acid-base (HSAB) theory. Main binding site in the anthocyanin modifier is $\mathrm{OH}$ group, which is a soft base whereas metals studied, $\mathrm{Pb}$ (II) and $\mathrm{Cu}$ (II) are intermediate and $\mathrm{Cd}(\mathrm{II})$ and $\mathrm{Zn}(\mathrm{II})$ are soft acids. According to HSAB theory, hard acids tend to form complexes with hard bases and soft acids tend to form complexes with soft bases. Hence, there should be strong bonding between same type of acids and bases in comparison with opposite type of species. On the basis of HSAB theory and the binding constants reported in the literature (Pandey et al. 2000), we can say that the order of binding is $\mathrm{Cu}(\mathrm{II})>\mathrm{Pb}$ (II) $>$ $\mathrm{Zn}$ (II) $>\mathrm{Cd}$ (II). On modifying further with gold nanoparticles, surface area is enhanced as we have seen, there is enhancement in detection of metal ions under study, and thus, interferences are reduced with GNAMCPE as compared to AMCPE (Table 1).

Determination of metals in the presence of surfactants

Surface active substances get adsorbed at the electrode surface and block them, disturbing deposition of the analyte. Surfactants differ in their effect on the electrode process depending on the type of surfactant, electrode and electroactive species. Thus, the characterization of electrode behavior in the presence of surfactants is an extremely complex undertaking. We have chosen three different surfactants as representatives for these experiments, including Triton X-100, sodium dodecyl sulfate (SDS) and cetyl trimethylammonium bromide (CTAB) commonly used as model surfactants. The effect of these surfactants was studied for determination of lead, cadmium and copper using GNMACPE. The surface of the same electrode was renewed and used each time, and the same electrode without any change was used for increasing amounts of the surfactant in solution.

Voltammogram in the presence of increasing amounts of each surfactant was recorded, and the effect of the surfactant on current value is shown in Fig. 8. GNAMCPE gave a well-defined stripping peak in absence of surfactant. 

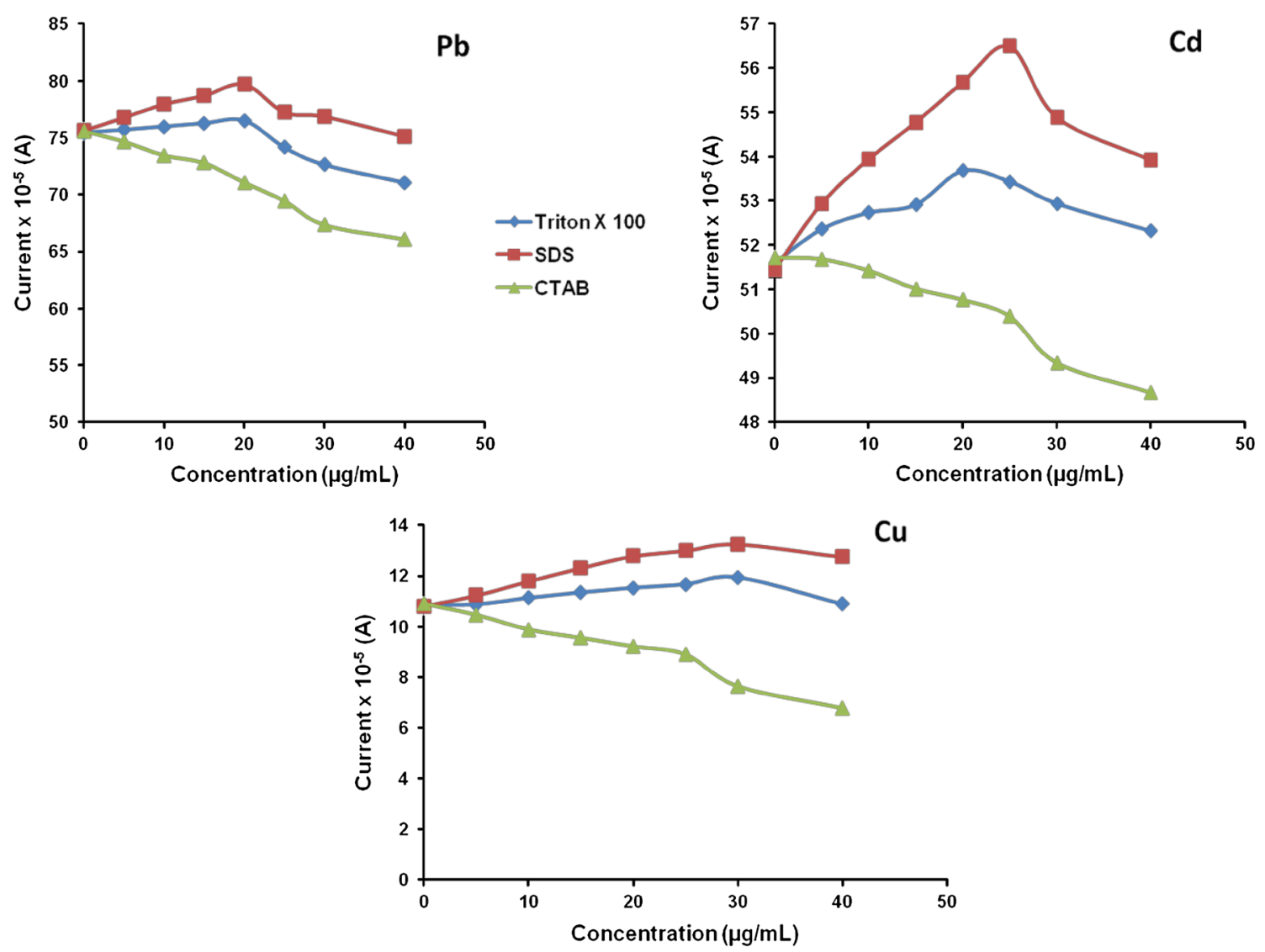

Fig. 8 Current response for $0.5 \mu \mathrm{g} \mathrm{mL} \mathrm{m}^{-} \mathrm{Pb}$ (II), $1 \mu \mathrm{g} \mathrm{mL} \mathrm{L}^{-}$cadmium and $0.5 \mu \mathrm{g} \mathrm{mL}{ }^{-}$of $\mathrm{Cu}(\mathrm{II})$ in the presence of increasing amounts of CTAB, Triton X-100 and SDS at GNMACPE under the optimized conditions

In case of $\mathrm{Pb}(\mathrm{II})$, Triton $\mathrm{X}-100$ did not show a major effect up to $20 \mu \mathrm{gL}^{-1}$. Beyond this, a gradual decrease in current values was observed, which may be attributed to electrode surface fouling. With CTAB, gradual decrease in current values initially up to $15 \mu \mathrm{gL}^{-1}$ was observed and on further increasing surfactant concentration, a steep decrease resulted. In contrast, SDS caused gradual increase in current values up to $20 \mu \mathrm{gL}^{-1}$ and a decrease in current values thereafter which may be again attributed to surface fouling.

In case of Cd (II), an almost similar trend as in case of $\mathrm{Pb}$ (II) was observed. Triton X-100 did not show a major effect up to $15 \mu \mathrm{gL}^{-1}$. Beyond $20 \mu \mathrm{gL}^{-1}$ of Triton $\mathrm{X}-100$, a gradual decrease in current values was observed, which may be attributed to electrode surface fouling. With CTAB, a gradual decrease in current values up to $25 \mu \mathrm{gL}^{-1}$ and a steep decrease beyond this concentration were observed. Whereas, with SDS gradual increase in current values up to $25 \mu \mathrm{gL}^{-1}$ was observed and decrease in current values thereafter which may be again attributed to surface fouling.

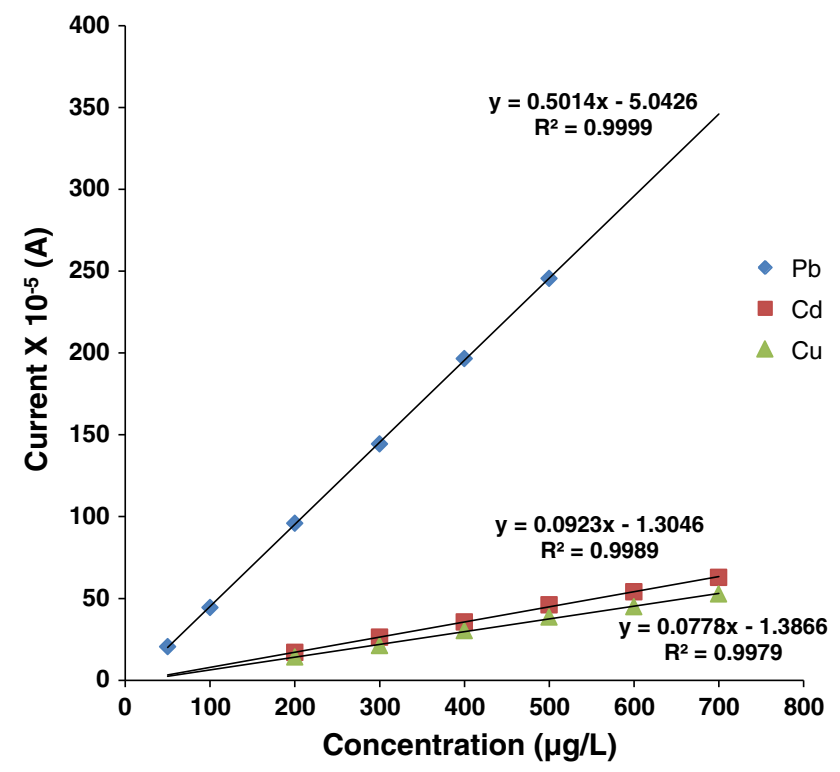

Fig. 9 Standard addition curve for determination of $\mathrm{Pb}$ (II), $\mathrm{Cd}$ (II) and $\mathrm{Cu}(\mathrm{II})$ obtained with a pre-concentration time of $3 \mathrm{~min}$ at GNMACPE under the optimized conditions 
Table 2 Analytical parameters for the determination of lead, cadmium and copper ions using GNMACPE by SWASV

\begin{tabular}{lllccll}
\hline Metal & Linear equation & $\mathrm{R}^{2}$ & $\mathrm{LOD}(\mu \mathrm{g} / \mathrm{L})$ & $\mathrm{LOQ}(\mu \mathrm{g} / \mathrm{L})$ & \multicolumn{2}{l}{$\mathrm{RSD}$} \\
\cline { 5 - 7 } & & & & & Intra-day (peak current) (\%) & Inter-day (peak current) $(\%)$ \\
\hline $\mathrm{Pb}(\mathrm{II})$ & $Y=0.5014 \mathrm{x}-5.0426$ & 0.999 & 9.178 & 30.594 & 1.534 & 2.013 \\
$\mathrm{Cd}(\mathrm{II})$ & $Y=0.0923 \mathrm{x}-1.0346$ & 0.999 & 86.327 & 287.757 & 2.656 & 3.125 \\
$\mathrm{Cu}(\mathrm{II})$ & $Y=0.0778 \mathrm{x}-1.3866$ & 0.998 & 85.373 & 284.576 & 2.214 & 2.809 \\
\hline
\end{tabular}

In case of $\mathrm{Cu}(\mathrm{II})$, again a similar trend as in case of $\mathrm{Pb}(\mathrm{II})$ and $\mathrm{Cd}(\mathrm{II})$ was observed. Triton $\mathrm{X}-100$ did not show a major effect up to $30 \mu \mathrm{gL}^{-1}$. With CTAB, a gradual decrease in current values up to $25 \mu \mathrm{gL}^{-1}$ and a steep decrease beyond this concentration were observed. With SDS in contrast, gradual increase in current values up to $30 \mu \mathrm{gL}^{-1}$ was observed and decrease in current values thereafter which may be again attributed to surface fouling.

Thus of all tested surfactants, Triton X-100 (non-ionic) did not show any significant effect. With increasing amount of CTAB (cationic), decrease in peak current was observed and with SDS (anionic), an increase in peak current was observed. The steep decrease beyond a particular concentration of surfactant that we observed can be attributed to fouling of electrode surface. The results support electrostatic interaction of metal ions with surfactants on electrode surface. This is in accordance with mechanism proposed that SDS displays a better catalytic activity for positively charged analytes (Zhang et al. 2008). No variation in the peak potential value was observed for metal solution containing surfactants.

Analytical parameters and method validation

The linearity between analytical signal and concentration of the analyte was recorded using different concentrations of the analyte under the optimal conditions determined. Well-defined signals were obtained for the target metal ion at different concentrations after $3 \mathrm{~min}$ accumulation for lead, cadmium and $4 \mathrm{~min}$ in case of copper. The relevant calibration plot (Fig. 9) serves as the basis for the quantification of the metal. The linearity of response, limit of detection (LOD), limit of quantification (LOQ) and precisions (i.e., intra-day and inter-day reproducibility) are summarized in Table 2.

For each metal, linear relationship was observed between the analytical signal and concentration ranging from 50 to 500,200 to 700 and 200 to $700 \mu \mathrm{g} \mathrm{L}^{-1}$ with a correlation coefficient of $0.999,0.999$ and 0.998 , respectively, for lead, cadmium and copper. The detection limit is evaluated to be about $9.178,86.327$ and $85.373 \mu \mathrm{g} \mathrm{L}^{-1}$ (S/ $N=3$ ).

For lead, the LOD reported is lowest as compared to that achieved with other plant-modified electrodes: kapok fiber $\left(1,000 \mu \mathrm{g} \mathrm{L}^{-1}\right)$; Pennisetum grass weed $\left(10 \mu \mathrm{g} \mathrm{L}^{-1}\right)$; feather $\left(590 \mu \mathrm{g} \mathrm{L}^{-1}\right)$; banana tissue $\left(100 \mu \mathrm{g} \mathrm{L}^{-1}\right)$; modified feather $\left(121 \mu \mathrm{g} \mathrm{L}^{-1}\right.$ ) (Mojica et al. 2002, 2005, 2007a, b; Ouangpipat et al. 2003). For cadmium and copper, there has not been much study on plant-modified carbon paste electrodes.

The reproducibility of the proposed method was studied by repeated determination of the metal mixtures by performing 10 repeated measurements in a day (intra-day precision), whereas inter-day precision was tested by triplicate quantifications for 4 days. The results are in good precision with relative standard deviation (RSD) of peak current less than $3.0 \%$ (intra-day precision) and lower than $4.0 \%$ (inter-day precision) as can be seen in Table 2. The results indicate that the proposed method has good precision for both qualitative and quantitative studies.

\section{Conclusion}

For preparation of gold nanoparticles, sodium tetrachloroaurate was directly mixed with anthocyanin extract of black rice in aqueous media without the intervention of any external man-made chemicals. Therefore, this reaction pathway satisfies all the conditions of a $100 \%$ green chemical process. Gold nanoparticles synthesized by this process are in nano range within $31-52 \mathrm{~nm}$ and spherical in morphology. The activity of the AMCPE for metal determination further increased using gold nanoparticles as their large surface to volume ratio offers enhanced electron transfer as indicated from CV and EIS results. This work thus offers green route for gold nanoparticle synthesis and 
also in terms of using an environment friendly modifier for carbon paste electrode to determine heavy metals at trace levels.

Acknowledgments Financial support from Ministry of Human Resource and Development, India, under NMEICT project (Grant Number: F.16-59/2011-TEL, dated 30-9-2011) is gratefully acknowledged.

\section{References}

Bartlett PN, Denuarret G, Souza MFB (2000) A study of the preconcentration and stripping voltammetry of $\mathrm{Pb}(\mathrm{II})$ at carbon electrodes. Analyst 125(6):1135-1138

Castaneda MT, Merkoci A, Pumera M, Alegret S (2007) Electrochemical genosensors for biomedical applications based on gold nanoparticles. Biosens Bioelectron 22(9-10):1961-1967

Chen JP, Wang L, Zou SW (2007) Determination of lead biosorption properties by experimental and modeling simulation study. Chem Eng J 131(1-3):209-215

Dai X, Nekrassova O, Hyde ME, Compton RG (2004) Anodic stripping voltammetry of arsenic(III) using gold nanoparticle modified electrodes. Anal Chem 76(19):5924-5929

Dai X, Wildgoose GG, Salter C, Crossley A, Compton RG (2006) Electroanalysis using macro-, micro-, and nonchemical architectures on electrode surfaces. Bulk surface modification of glassy carbon microspheres with gold nanoparticles and their electrical wiring using carbon nanotubes. Anal Chem 78(17): 6102-6108

Daniel M, Astruc D (2004) Gold nanoparticles: assembly, supramolecular chemistry, quantum-size-related properties, and applications toward biology, catalysis, and nanotechnology. Chem Rev 104(1):293-346

El-Deab MS, Okajima T, Ohsaka T (2003) Electrochemical reduction of oxygen on gold nanoparticle-electrodeposited glassy carbon electrodes. J Electrochem Soc 150(7):A851-A857

Elvina RO Jr, Mojica ERE (2005) Orange peel essential oil as component of a metal sensor for lead (II) ion determination in aqueous solutions. J Appl Sci Environ Mgt 9(2):23-27

Gardea-Torresdey J, Darnall D, Wang J (1988) Bioaccumulation and measurement of copper at an alga-modified carbon paste electrode. Anal Chem 60(1):72-76

Iqbal M, Saeed A, Zafar SI (2007) Hybrid biosorbent: an innovative matrix to enhance the biosorption of $\mathrm{Cd}(\mathrm{II})$ from aqueous solution. J Hazard Mater 148(1-2):47-55

Ishida T, Haruta M (2007) Gold catalysis: towards sustainable chemistry. Angew Chem Int Ed 46(38):7154-7156

Jannata B, Sadeghib N, Oveisib MR, Behfarc A, Komeilizadehd H, Shafaatid A (2009) Simultaneous determination of lead, cadmium, copper and zinc in Infant formula by anodic stripping voltammetry. Iran J Pharm Res 8(3):159-162

Javanbakht M, Khoshafar H, Ganjali MR, Badiei A, Norouzi P, Hasheminasab A (2009) Determination of nanomolar mercury (II) concentration by anodic stripping voltammetry at a carbon paste electrode modified with functionalized nanoporous silica gel. Curr Anal Chem 5(1):35-41

Kneipp K, Kneipp H, Kneipp J (2006) Surface-enhanced Raman scattering in local optical fields of silver and gold
nanoaggregates-FROM single molecule Raman spectroscopy to ultrasensitive probing in live cells. Acc Chem Res 39(7):443-450

Majid E, Hrapovic S, Liu Y, Male KB, Luong JHT (2006) Electrochemical determination of arsenite using a gold nanoparticle modified glassy carbon electrode and flow analysis. Anal Chem 78(3):762-769

Mohadesi A, Teimoori E, Taher MA, Beitollah H (2011) Adsorptive stripping voltammetric determination of cobalt (II) on the carbon paste electrode. Int J Electrochem Sci 6(2):301-308

Mojica ERE, Merca FE, Micor JRL (2002) Fiber of Kapok (Ceiba pentandra) as component of a metal sensor for lead in water samples. Philipp J Crop Sci 27(2):37-42

Mojica ERE, Micor JRL, Deocaris CC (2005) KaCCFEHM-trode, an example of a radiation synthesized metal sensor with a multi composite modifier. J Appl Sci Res 1(1):99-102

Mojica ERE, Gomez SP, Micor JRL, Deocaris CC (2006) Lead detection using a pineapple bioelectrode. Philipp Agric Sci 89(2):134-140

Mojica ERE, Santos JH, Micor JRL (2007a) Determination of lead using a feather modified carbon paste electrode by anodic stripping voltammetry. World Appl Sci J 2(5):512-518

Mojica ERE, Vidal JM, Pelegrina AB, Micor JRL (2007b) Voltammetric determination of lead (II) ions at carbon paste electrode modified with banana tissue. J Appl Sci 7(9):1286-1292

Nune SK, Chanda N, Shukla R, Katti K, Kulkarni RR, Thilakavathy S, Mekapothula S, Kannan R, Katti KV (2009) Green nanotechnology from tea: phytochemicals in tea as building blocks for production of biocompatible gold nanoparticles. J Mater Chem 19(19):2912-2920

Ouangpipat W, Lelasattarathkul T, Dongduen C, Liawruangrath S (2003) Bioaccumulation and determination of lead using treatedPennisetum-modified carbon paste electrode. Talanta 61(4): $455-464$

Oyama M (2010) Recent nanoarchitectures in metal nanoparticles modified electrodes for electroanalysis. Anal Sci 26(1):1-12

Pandey AK, Pandey SD, Misra V (2000) Stability constants of metalhumid acid complexes and its role in environmental detoxification. Ecotoxicol Environ Saf 47(2):195-200

Park Sam Y, Kim SJ, Chang HI (2008) Isolation of anthocyanin from black rice (Heugjinjubyeo) and screening of its antioxidant activities. Kor J Microbiol Biotechnol 36(1):55-60

Ramos JA, Bermejo E, Zapardiel A, Perez A, Hernandez L (1993) Direct determination of lead by bioaccumulation at a mossmodified carbon paste electrode. Anal Chim Acta 273(1-2): 219-227

Rezaei B, Damiri S (2008) Multiwalled carbon nanotubes modified electrode as a sensor for adsorptive stripping voltammetric determination of hydrochlorothiazide. IEEE Sens J 8(9): 1523-1529

Rodriguez-Saona LE, Wrolstad RE (2011) Unit F2.1 anthocyanins: extraction, isolation and purification of anthocyanins. In: King S, Gates M, Scalettar L (eds) Current protocols in food analytical chemistry. Wiley, New York, pp 1-11

Welch CM, Banks CE, Simm AO, Compton RG (2005) Silver nanoparticles assemblies supported on glassy-carbon electrodes for the electro-analytical detection of hydrogen peroxide. Anal Bional Chem 382(1):12-21

Wu CC, Chen DH (2010) Facile green synthesis of gold nanoparticles with gum arabic as a stabilizing agent and reducing agent. Gold Bull 43(4):234-240 
Xia F, Zhang X, Zhou C, Sun D, Dong Y, Liu Z (2010) Simultaneous determination of copper, lead and cadmium at hexagonal mesoporous silica immobilized quercetin modified carbon paste electrode. J Autom Method Manag Chem. doi:10.1155/2010/ 824197

Yardim Y, Senturk Z (2011) Voltammetric behavior of indole-3acetic acid and kinetin at pencil-lead graphite electrode and their simultaneous determination in the presence of anionic surfactant. Turk J Chem 35(3):413-426
Zhang MW, Guo BJ, Zhang RF, Chi JW, Wei ZC, Xu ZH, Zhang Y, Tang XJ (2006) Separation, purification and identification of antioxidant compositions in black rice. Agric Sci China 5(6):431-440

Zhang X, Ju H, Wang J (2008) Electrochemical sensors, biosensors and their biochemical applications. Academic Press, USA 